\title{
Effect of Flask Types, Post-pressing Times and Base Regions on the Adaptation of Complete Dentures
}

\author{
Marinaldo Henrique Zampieri ${ }^{1}$, Rafael Leonardo Xediek Consani ${ }^{2}$, Marcelo Ferraz \\ Mesquita $^{3}$, Leonardo Marchini ${ }^{4}$ and Mateus Bertolini Fernandes dos Santos ${ }^{5}$ \\ ${ }^{1,2,3,5}$ Department of Prosthodontics and Periodontics, Piracicaba Dental School, State University of \\ Campinas, 901 Limeira Ave., 13414-903, Piracicaba, SP, Brazil
}

${ }^{4}$ Department of Preventive and Community Dentistry, College of Dentistry, University of lowa, USA

Correspondence should be addressed to: Rafael Leonardo Xediek Consani, rconsani@fop.unicamp.br Received date: 18 October 2013; Accepted date: 28 November 2013; Published date: 14 March 2014 Academic Editor: Josip Kranjčić

Copyright (C) 2014. Marinaldo Henrique Zampieri, Rafael Leonardo Xediek Consani, Marcelo Ferraz Mesquita, Leonardo Marchini and Mateus Bertolini Fernandes dos Santos. Distributed under Creative Commons CC-BY 3.0

\begin{abstract}
This study aimed to evaluate the effect of flask types, post-pressing times and base regions on the base adaptation of maxillary and mandibular complete dentures. Denture bases were waxed in stone casts and randomly divided into six groups $(n=10)$, according to conventional and double flasks inclusion, and immediate and 6 hours post-pressing times. Denture bases were polymerized in water bath at $74^{\circ} \mathrm{C}$ for 9 hours. Stone cast-denture base sets were sectioned in three regions corresponding to: A- distal of canines, B- mesial of first molars, and C- posterior palatal seal (maxillary base) or tubercle region (mandibular base). Stone cast-denture base set adaptation was verified on reference points of maxillary and mandibular denture bases with a comparative linear microscope with $0.0005 \mathrm{~mm}$ accuracy. Obtained data were analyzed by the ANOVA and Tukey's test $(\alpha=0.05)$.For maxillary and mandibular denture bases at immediate polymerization, all regions showed lower misfit values for the traditional flask with statistical significance when compared to double flask. No statistically significant difference was shown after 6 hour post-pressing time. Except in the region A for the maxillary denture base in the traditional flask, other regions showed significantly different values when the immediate and 6 hour post-pressing times were compared. No statistical significance was observed for the mandibular denture base. Traditional flask and immediate post-pressing time promoted better adaptation than double flask for maxillary and mandibular denture bases. In 6-hour post-pressing time, similar base adaptation was shown for both traditional and double flasks for all regions.
\end{abstract}

Keywords: Complete denture base; Flask type; Post-pressing time; Denture base adaptation 


\section{Introduction}

A previous study has shown that linear dimensional changes of acrylic resins are an important property for complete denture adaptation, in which the resin pressing procedure and polymerization cycle are factors that exert effects on the denture base distortion (Harman, 1949). The linear dimensional change that occurs during denture processing is always related to complete denture adaptation (Miéssi et al., 2008 and Consani et al., 2009). However, the water absorption by the denture base, gingival resilience and saliva between the denture base and the soft tissue can compensate, in part, the inaccuracy caused by the denture procedure (Jacobson \& Kroll, 1983 and Polyzois, 1990).

Some studies have proposed alternative techniques to conventional procedures of polymerization, such as microwave energy irradiation (Nishii, 1968), dry-heat (Gay \& King, 1979), fast cycling in boiled water (Polyzois et al., 1987) and polymerization by visible light (Takamata \& Setcos, 1989). Despite these techniques, the most efficient and accepted cycle for denture processing is the long cycle with hot water bath (Anusavice, 2003). However, the literature has also shown satisfactory results when acrylic resin denture base is polymerized by either microwave irradiation (Wallace et al., 1991) or fast cycle in boiled water bath (Polyzois et al., 1987).

After denture processing, the denture base adaptation level should not be changed, whatever the method used for acrylic resin polymerization. However, the literature has shown that the adaptation between denture base and stone cast is still unsatisfactory, mainly in the posterior palatal region (Sykora \& Sutow, 1993; Consani et al., 2002a and Consani et al., 2007). The adaptation of the denture base is also influenced by other variables, such as palate vault shape (Sykora \& Sutow, 1993), commercial types of acrylic resin (Consani et al., 2002b), flask closure methods (Consani et al., 2007), and it is still considered an unresolved and critical problem (Consani et al., 2007; Pavan et al., 2005 and Huggett et al., 1992).

Under dental laboratory routine, the polymerization shrinkage of acrylic resins, the thermal cooling of flasks and the distortion due to release of tensions during deflasking are also factors responsible for the decreased quality of the denture base adaptation (Takamata \& Setcos, 1989).]

In recent years, previous works have investigated the influence of different double flasks for denture procedure. Double plastic flask (HHF; VIPI Dental Products, Pirassununga, SP, Brazil) was used to reduce tooth displacement in complete dentures during microwave irradiation curing procedure (RizzattiBarbosa et al. 2005 and Farias-Neto et al., 2012) and to verify the influence of different investing and flasking techniques (Sotto-Maior et al., 2012). The results showed that double flasking technique did not decrease the tooth movement, but could compensate the displacement by the simultaneous movement occurred on maxillary and mandibular teeth processed in occlusion (Rizzatti-Barbosa et al., 2005) and the molar inclination was similar for single and double flasks (Farias-Neto et al., 2012). Comparing traditional and experimental metal double flasks, earlier work showed that there is no evidence that different flask systems cause different teeth displacement in complete dentures processed by moist hot-curing (Santos et al., 2012). A more recent study has shown that framework misfit values were decreased when double flasks were used in mandibular fixed implant-supported complete dentures procedure (Caetano et al., 2013).

Based on these considerations, the purpose of this study was to investigate the accuracy of maxillary and mandibular denture bases influenced by flask types (traditional and double), post-pressing times (immediate and 6 hours) and denture base regions (A, B, and $\mathrm{C})$. The work hypothesis would be that different 
flasks, post-pressing times and base regions can differently influence the level of adaptation of the acrylic resin denture base on the stone cast.

\section{Materials and Methods}

Silicone molds (Elite Double; Zhermack, Rovigo, Italy) simulating edentulous maxillary and mandibular arches with no irregularities in the alveolar ridge were used. Maxillary and mandibular stone casts were poured in type III dental stone (Herodent Soli-Rock; Vigodent, Petropolis, RJ, Brazil). A uniform wax baseplate with a 2.0-mm thickness was made on each stone cast by the same technician and randomly divided into six groups $(n=10)$, according to Table 1 . Sixty specimens were included in study $(n=10)$.

Table 1: Experimental groups

\begin{tabular}{|c|c|c|c|}
\hline & Denture base & Flask type & Post-pressing time \\
\hline Group 1 & Maxillary & Traditional & Immediate \\
\hline Group 2 & Maxillary & Traditional & 6 hours \\
\hline Group 3 & Maxillary/Mandibular & Double & Immediate \\
\hline Group 4 & Maxillary/Mandibular & Double & Immediate \\
\hline Group 5 & Mandibular & Traditional & 6 hours \\
\hline Group 6 & Mandibular & Traditional & \\
\hline
\end{tabular}

Maxillary and mandibular cast-wax baseplate sets of the groups 1, 2, 5 and 6 were individually invested in the lower part of traditional brass flasks (Safrany; Safrany Dental Metallurgy, Sao Paulo, SP, Brazil) with type II dental plaster (Pasom; Pasom Manufacturing and Trade, Sao Paulo, SP, Brazil). Using the same pour investment method, the maxillary and mandibular casts of the groups 5 and 6 were invested together in separate compartments of an experimental metal double flask that was especially developed for this study (Brazilian patent MU8.200.888-4 held by the State University of Campinas). The flask assemblies were fixed with screws (Figure 1). Petroleum jelly was used as a separating medium for the plaster. Type III dental stone (Herodent Soli-Rock) was used to invest the upper portion of the flasks.

Marinaldo Henrique Zampieri, Rafael Leonardo Xediek Consani, Marcelo Ferraz Mesquita, Leonardo Marchini and Mateus Bertolini Fernandes dos Santos (2014), Journal of Research and Practice in Dentistry DOI: $10.5171 / 2014.948878$ 


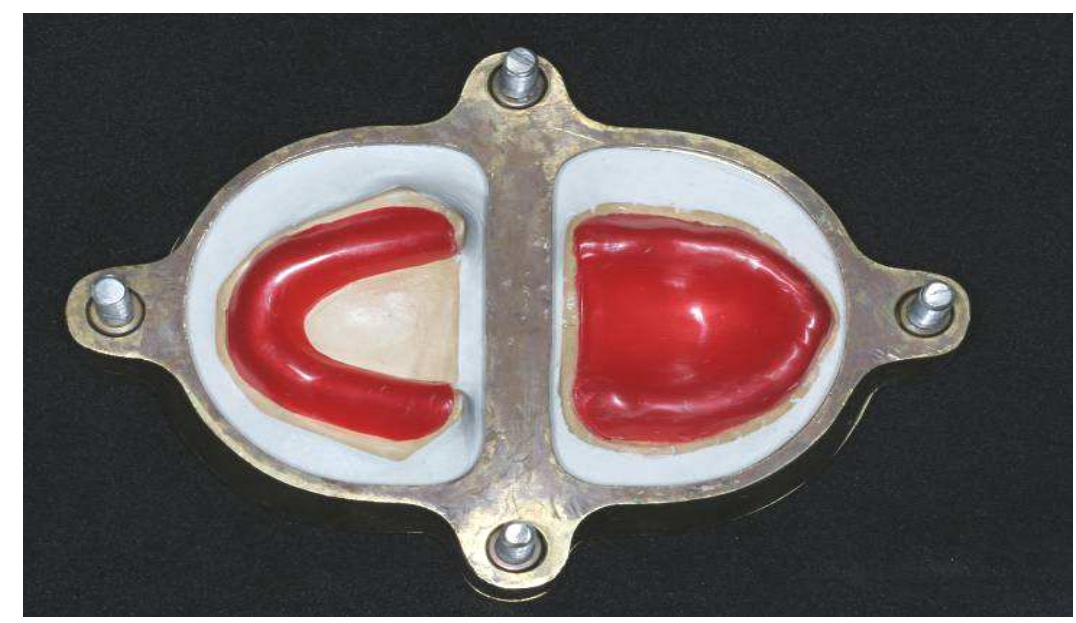

Figure 1 - Experimental double flask fixed with screws

After the investing material had set, the wax baseplates were removed from the casts and the stone cleaned with a solution of hot water and liquid detergent (Ype; Amparo Chemical Products, Amparo, SP, Brazil). One coat of sodium alginate (Isolak; Classico Dental Products, Sao Paulo, SP, Brazil) was used as a separating medium. PMMA dough (Classico; Classico Dental Products) was prepared with a $35.5 \mathrm{~g}$ powder to $15 \mathrm{~mL}$ liquid ratio, according to the manufacturer's instructions and packed in the dough-like stage. A polyethylene sheet was used as a separating medium during the initial flask packing under a load of $850 \mathrm{kgf}$ in a hydraulic press (Linea $\mathrm{H}$; Linea, Sao Paulo, SP, Brazil).

Traditional flasks (groups 1, 2, 5 and 6) were placed in traditional metallic clamps after final pressing in a hydraulic press (Linea H; Linea, Sao Paulo, SP, Brazil) under 1,250 kgf for 5 minutes (Consani et al., 2002a). For the double flask technique (groups 3 and 4), the trial pack at definitive closure was similar to the traditional flask; however, after the final pressing the flask, assemblies were fixed with screws. The flasks for the immediate group were immediately immersed after flask closure in water at room temperature and polymerized at $74^{\circ} \mathrm{C}$ for 9 hours. Flasks, for polymerization after the 6-hour postpressing time, were processed under similar conditions to those of the immediate group and stored at room temperature for 6 hour prior to the polymerization procedure. The polymerizing unit (Termotron; Termotron Laboratory Products, Piracicaba, SP, Brazil) was programmed to raise the temperature to $74^{\circ} \mathrm{C}$ for 1 hour and then maintained at $74^{\circ} \mathrm{C}$ for 8 hours.

After flask cooling at room temperature, the denture base was carefully deflasked without damaging the stone cast and the resin excess was trimmed. All bases were returned to their corresponding casts and fixed with instantaneous adhesive (Super Bonder; Loctite, Barueri, SP, Brazil) placed on the ridge crest of the stone cast, under a pressure of $1 \mathrm{kgf}$ for 1 minute. The denture base-stone cast sets were transversally sectioned in a sawing device into three parts, corresponding to the regions: Adistal of canines; B- mesial of first molars; and $\mathrm{C}$ - posterior palatal seal (maxillary base) or tubercle region (mandibular base). The sawing movement was very slow to avoid heat generation and possible dimensional change in the denture resin base.

The gap between the internal border of the base and the external border of the stone cast was measured in the three regions at the following referential points: 1Maxillary cast/base set: a- right and left marginal limits of the flanges; $b$ - right and left alveolar ridge crests; c- posterior palatal midline; and 2- Mandibular

Marinaldo Henrique Zampieri, Rafael Leonardo Xediek Consani, Marcelo Ferraz Mesquita, Leonardo Marchini and Mateus Bertolini Fernandes dos Santos (2014), Journal of Research and Practice in Dentistry, DOI: 10.5171/2014. 948878 
cast/base set: a- right and left marginal limits of the buccal and lingual flanges; and b- right and left alveolar ridge crests. An optical micrometer (Olympus Optical; Tokyo, Japan) with tolerance of $0.0005 \mathrm{~mm}$ was used for measurement purposes. The mean of the reference points of each region (A, B or C) was considered as the arithmetic average of the region.

Obtained data were submitted to threeway ANOVA, and the factors studied were flask, post-pressing time, and denture base region. The interactions were also verified. The means were compared by Tukey's test at a significance level of $\alpha=0.05$.

\section{Results}

Table 2 shows mean values and SD of the maxillary base adaptation $(\mathrm{mm})$ for each region when the flask and post-pressing time interaction was analyzed. When immediate and 6-hour post-pressing times were compared, only the region A demonstrated no statistically significant difference for the traditional flask. When the flasks were compared, statistically significant differences were observed for all regions in the immediate post-pressing time. In the same comparison, values for the 6-hour post-pressing time showed no statistically significant differences in all regions.

Table 2: Mean values (SD) of the maxillary base adaptation ( $\mathrm{mm}$ ) for each region, in relation to flask and post-pressing time interaction

\begin{tabular}{|c|c|c|c|}
\hline Region & Flask type & \multicolumn{2}{|c|}{ Post-pressing time } \\
\hline & & Immediate & 6 hours \\
\hline $\mathbf{A}$ & Traditional & $0.107(0.02) \mathrm{Ab}$ & $0.130(0.03) \mathrm{Aa}$ \\
\hline & Double & $0.200(0.07) \mathrm{Aa}$ & $0.110(0.02) \mathrm{Ba}$ \\
\hline $\mathbf{B}$ & Traditional & $0.134(0.03) \mathrm{Bb}$ & $0.189(0.07) \mathrm{Aa}$ \\
\hline & Double & $0.268(0.05) \mathrm{Aa}$ & $0.167(0.04) \mathrm{Ba}$ \\
\hline $\mathbf{C}$ & Traditional & $0.199(0.06) \mathrm{Bb}$ & $0.243(0.09) \mathrm{Aa}$ \\
\hline & Double & $0.349(0.08) \mathrm{Aa}$ & $0.241(0.06) \mathrm{Ba}$ \\
\hline
\end{tabular}

Means followed by different capital letters in each row and lowercase letters in each column for each region are significantly different by Tukey's test (5\%).

Mean values and SD of the mandibular base adaptation $(\mathrm{mm})$ for each region, in relation to flask and post-pressing time interaction are shown in Table 3. When immediate and 6-hour post-pressing times were compared, there was statistical similarity in all regions for both flasks. When the flasks were compared, there was statistically significant difference in all regions only for the immediate post-pressing time.

Marinaldo Henrique Zampieri, Rafael Leonardo Xediek Consani, Marcelo Ferraz Mesquita, Leonardo Marchini and Mateus Bertolini Fernandes dos Santos (2014), Journal of Research and Practice in Dentistry DOI: $10.5171 / 2014.948878$ 
Table 3 : Mean values (SD) of the mandibular base adaptation ( $\mathrm{mm}$ ) for each region, in relation to flask and post-pressing time interaction

\begin{tabular}{|c|c|c|c|}
\hline Region & Flask type & \multicolumn{2}{|c|}{ Post-pressing time } \\
\hline & & Immediate & 6 hours \\
\hline A & Traditional & $0.109(0.06) \mathrm{Ab}$ & $0.137(0.04) \mathrm{Aa}$ \\
\hline & Double & $0.208(0.05) \mathrm{Aa}$ & $0.145(0.02) \mathrm{Aa}$ \\
\hline B & Traditional & $0.141(0.05) \mathrm{Ab}$ & $0.194(0.06) \mathrm{Aa}$ \\
\hline & Double & $0.240(0.03) \mathrm{Aa}$ & $0.170(0.02) \mathrm{Aa}$ \\
\hline C & Traditional & $0.158(0.06) \mathrm{Ab}$ & $0.249(0.09) \mathrm{Aa}$ \\
\hline & Double & $0.280(0.06) \mathrm{Aa}$ & $0.194(0.03) \mathrm{Aa}$ \\
\hline
\end{tabular}

Means followed by different capital letters in each row and lowercase letters in each column for each region are significantly different by Tukey's test (5\%).

\section{Discussion}

The hypothesis of this in vitro study that different flasks and post-pressing times could influence the adaptation of acrylic resin denture bases on the stone cast was partially confirmed.

Previous studies have shown that the posterior region of maxillary bases may be considered as an important factor for complete denture distortion (Takamata \& Setcos, 1989; Woelfel et al., 1960; Antony \& Peyton, 1962; Sanders et al., 1991; Woelfel \& Paffenberger, 1965 and Lechner \& Lautenschlager, 1984), and more recent studies have confirmed that this region always presents the worst adaptation (Consani et al., 2007; Pavan et al., 2005; Shukor et al., 2006 and Pasam et al., 2012).

In the current study, this distortion pattern of the denture base was not influenced by the association flask and post-pressing time, confirming the results of studies reporting that the greatest distortion always occurs in the midline of the posterior palatal seal ( Sykora \& Sutow, 1993; Consani et al., 2002a;
Consani et al., 2007; Consani et al., 2002b; Pavan et al., 2005; Woelfel et al., 1960; Antony \& Peyton, 1962; Sanders et al., 1991; Woelfel \& Paffenberger, 1965; Lechner \& Lautenschlager, 1984 and Pasam et al., 2012). However, the work variables had also significant influence on the adaptation of the maxillary and mandibular bases when the denture was considered as a whole, mainly for the polymerization in the immediate postpressing time.

Although the anatomical regions are different for the maxillary and mandibular arches, both denture bases showed similar patterns of adaptation. Probably, this occurrence was due to the fact that the maxillary arch shows a region with best retention (anterior) and another with worse retention (posterior palatal seal), while the mandibular arch presents region with best (anterior) and worse (posterior with free ends) retentions. Thus, when the denture bases were considered as a whole, they showed similar patterns of adaptation in each region for both denture bases.

A previous study showed that better base adaptation occurs on the anterior portion (Consani et al., 2007). This fact appears to be resulting from the association between the anatomic condition of the anterior region and the polymerization shrinkage of the acrylic

Marinaldo Henrique Zampieri, Rafael Leonardo Xediek Consani, Marcelo Ferraz Mesquita, Leonardo Marchini and Mateus Bertolini Fernandes dos Santos (2014), Journal of Research and Practice in Dentistry, DOI: 10.5171/2014. 948878 
resin. On the anterior region, the stress released after denture processing does not cause significant base distortion. Conversely, the anatomical form of the posterior region should allow larger distortion, causing more inaccuracy of the base, whatever the variables studied (Consani et al., 2007). In the current study, for both denture bases the flask and post-pressing time association did not influence the pattern of distortion showed in the literature, confirming that the worst adaptation occurs always in the less retentive region and more liable to distortion occurrences.

With the exception of the A region for the maxillary base in the traditional flask, all regions presented values with statistical differences when the post-pressing times were compared in the traditional and double flasks (Table 2). In the immediate time, the values for all regions were lower in the traditional flask; however, no difference was observed at the 6-hour post-pressing time. These findings show the complexity involved in the complete denture processing, mainly when these factors are associated.

With the exception of the A region, the adaptation level of the maxillary denture base processed in the traditional flask does not agree with the statistical similarity between the immediate and 6-hour postpressing times showed in earlier study (Consani et al., 2004). As claimed, the traditional closure permits flask opening prior to placing the flask in the clamp. This fact allows similar level of relieved internal stress from the resin mass before the polymerization cycle for immediate and 6hour post-pressing times (Consani et al., 2004).

Conversely, difference was observed in the A region for the maxillary base processed by double flask when post-pressing times were compared, showing better adaptation for the 6-hour time. Based on the data of the present study, this result is difficult to explain and understand. It may be speculated that the double flask permitted a more efficient flash of the resin mass and the release of internal stress during the 6-hour waiting time before the polymerization. However, as this fact did not occurr for the mandibular base processed in the double flask, further studies are necessary to fully understand and clarify these findings.

Significant difference was found for all regions for the immediate time, with the double flask causing higher inaccuracy for the maxillary bases (Table 2). This result highlights the differences between the flasks, causing different effects on the adaptation level of the denture bases. Conversely, for the 6-hour post-pressing time, no significant differences were found in any of the regions for the maxillary base. Probably, the 6-hour delayed time standardized the release of stress induced during the denture processing, minimizing the distortion of the base caused by both flasks. As described in earlier study (Peyton, 1950), one reason for allowing the flask to stand for at least 1 hour is to permit the flash of the resin mass into all regions of the mold and, thus, relieve internal stresses during the early stage of flask closure. In addition, another important factor is that the major disadvantage of techniques for making complete dentures is also the deformation that occurs upon removal of the polymerized resin base from the stone cast (Sanders et al., 1991 and Grunewald et al., 1952).

When mandibular base adaptation for each region was considered between flasks (Table 3 ), significant difference was found in all regions for the immediate time. The values obtained with the traditional flask were lower and different from those showed by the double flask. Another important fact is that the adaptation pattern of the mandibular base for the immediate time in each region was similar to those showed by the maxillary base when the traditional and double flasks were compared. This finding is also difficult to clarify due to the same reason discussed for the maxillary base. It is probable that the flasks had significantly influenced the results despite the anatomical difference between arches.

However, at the 6-hour post-pressing time, no difference between the flasks was observed for all regions, signifying that the delay for the start of the polymerization compensated the influence of the flasks,

Marinaldo Henrique Zampieri, Rafael Leonardo Xediek Consani, Marcelo Ferraz Mesquita, Leonardo Marchini and Mateus Bertolini Fernandes dos Santos (2014), Journal of Research and Practice in Dentistry DOI: $10.5171 / 2014.948878$ 
stabilizing the discrepancies promoted between maxillary and mandibular bases occurred in the immediate procedure. As claimed, an increased delay time for polymerization of at least 1 hour allows the flow of the resin mass inside the mold and the release of internal stresses, promoting an improved level of adaptation of the denture base (Peyton, 1950). However, this fact was evident only for the maxillary base in the double flask (Table 2). In despite of the complexity that involves the processing of complete dentures, this study showed the importance of associated effects as flask type and post-pressing time on the dimensional accuracy of the acrylic resin bases.

According to previous study, the magnitude of the distortions on a scale of -0.05 to +0.20 $\mathrm{mm}$ did not significantly affect the performance of the prosthesis in use (Mowery et al., 1958). Thus, the present study shows possible limitations in the adaptation level of the denture base made with the double flask. By this reason, the double flask should be used with restrictions as a technique for immediate polymerization for complete denture processing, since it presented higher distortion values than the recommended by those authors (Mowery et al., 1958).

In complete denture wearers, other factors that are clinically involved in retention should be considered, such as wettability of the denture surface, the presence of an efficient border seal, salivary viscosity and seating force. In addition, the loss of base adaptation and border seal as a result of the base plate distortion remains the most significant factor that affects the denture stability (Ellis et al., 2004).

\section{Conclusion}

Within the limitations of this in vitro study, the following conclusions can be drawn: The adaptation of maxillary and mandibular denture bases was influenced differently by flask types, post-pressing times and denture base regions. Traditional flask and immediate polymerization promoted better adaptation for maxillary and mandibular bases. In all denture bases, increased post-pressing time showed similar adaptation for traditional and double flasks.

\section{Conflict of Interest Statement}

The authors claim to have no financial interest, directly or indirectly, in any commercially products mentioned in this article.

\section{Acknowledgements}

The authors wish to thank the Co-ordination of Personnel Improvement of Higher Education (CAPES) for the support to PostGraduation Program at Piracicaba Dental School, State University of Campinas, SP, Brazil.

\section{References}

1. Anthony, D. H, Peyton, F. A. (1962) "Dimensional accuracy of various denturebase materials." Journal of Prosthetic Dentistry, 12 (1) 67-81.

2. Anusavice, K.J. (2003) Phillips' Science of Dental Materials. 10th ed. Saunders, St. Louis, 709 p.

3. Caetano, C. R, Consani, R. L. X, Bacchi, A, Correr, A. B and Santos, M. B. F. (2013) "Influence of diferente flask systems on tooth displacement and framework misfit in mandibular fixed implant-supported complete dentures". Journal of Prosthodontic Research, 57 (3) 213-218.

4. Consani, R. L, Domitti, S. S and Consani, S. (2002a) "Effect of a new tension system, used in acrylic resin flasking, on the dimensional stability of denture bases". Journal of Prosthetetic Dentistry, 88 (3) 285289.

5. Consani, R. L, Domitti, S. S, RizzattiBarbosa, C. M and Consani, S. (2002b) "Effect of commercial acrylic resins on dimensional accuracy of the maxillary denture base." Brazilian Dental Journal, 13 (1) 57-60.

6. Consani, R. L, Domitti, S. S, Mesquita, M. F and Consani, S. (2004) "Effect of packing types on the dimensional accuracy of denture base resin cured by the conventional cycle in

Marinaldo Henrique Zampieri, Rafael Leonardo Xediek Consani, Marcelo Ferraz Mesquita, Leonardo Marchini and Mateus Bertolini Fernandes dos Santos (2014), Journal of Research and Practice in Dentistry, DOI: 10.5171/2014. 948878 
relation to post-pressing times." Brazilian Dental Journal, 15 (1) 63-67.

7. Consani, R. L, Mesquita, M. F, Nobilo, M. A. A and Henriques, G. E. P. (2007) "Influence of simulated microwave disinfection on complete denture base adaptation using different flask closure methods." Journal of Prosthetic Dentistry, 97 (3) 173-178.

8. Consani, R. L. X, Mesquita, M. F, CorrerSobrinho, L and Sinhoreti, M. A. C. (2009) "Dimensional accuracy of upper complete denture bases: the effect of metallic flask closure methods." Gerodontology, 26 (1) 5864.

9. Ellis, J. S, Read, G. E and Thomason, J. M. (2004) "A subjective study of dimensional stability of permanent acrylic resin complete denture bases after a second curing cycle." European Journal of Prosthodontics and Restorative Dentistry, 12 (3) 105-108.

10. Farias-Neto, A, Santos-Sousa, R. L and Rizzatti-Barbosa, C. M. (2012) "The influence of double flask investment on tooth displacement in dentures processed by microwave irradiation." Gerodontology, 29 (2) e929-e929.

11. Gay, W. D and King, G. E. (1979). "An evaluation of the cure of acrylic resin by three methods." Journal of Prosthetic Dentistry, 42 (4) 437-440.

12. Grunewald, A. H, Paffenbarger, G. C and Dickson, G. (1952) "The effect of molding processes on some properties of denture resins." Journal of American Dental Association, 44 (3) 269-284.

13. Harman, I. M. (1949) "Effects of time and temperature on polymerization of a methacrylate resin denture base." Journal of American Dental Association, 38 (2) 188-203.

14. Huggett, R, Zissis, A, Harrison, A and Dennis, A. (1992) "Dimensional accuracy and stability of acrylic resin denture bases." Journal of Prosthetic Dentistry, 68 (4) 634640.
15. Jacobson, T. E and Krol, A. J. (1983). “A contemporary review of the factors involved in complete dentures. Part III: support." Journal of Prosthetic Dentistry, 49 (3) 306313.

16. Lechner, S. K and Lautenschlager, E. P. (1984) "Processing changes in maxillary complete dentures." Journal of Prosthetic Dentistry, 52 (1) 20-24.

17. Miéssi, A. C, Goiato, M. C, Santos, D. M, Dekon, M. S and Okida, R. C. (2008) "Influence of storage period and effect of different brands of acrylic resin on the dimensional accuracy of the maxillary denture base." Brazilian Dental Journal, 19 (3) 204-208.

18. Mowery, W. E, Burns, C. L, Dickson, G and Sweeney, W. T. (1958) "Dimensional stability of denture base resins." Journal of American Dental Association, 57 (3) 345-353.

19. Nishii, M. (1968) "Curing of denture base resins with microwave irradiation: with particular reference to heat-curing resins." Journal of Osaka Dental University, 2 (1) 2340.

20. Pasam, N, Hallikerimath, R. B, Arora, A and Gilra, S. (2012) "Effect of different curint temperatures on the distortion at the posterior peripheral seal: an in vitro study." Indian Journal of Dental Research, 23 (3) 301304.

21. Pavan, S, Arioli-Filho, J. N, Santos, P. H and Mollo Jr F. A. (2005) "Effect of microwave treatments on dimensional accuracy of maxillary acrylic resin denture base." Brazilian Dental Journal, 16 (2) 119-123.

22. Peyton, F. A. (1950) "Packing and processing denture base resins." Journal of American Dental Association, 40 (5) 520-528.

23. Polyzois, G. L, Karkazis, H. C, Zissis, A. J and Demetriou, P. P. (1987) "Dimensional stability of dentures processed in boilable acrylic resins: a comparative study." Journal of Prosthetic Dentistry, 57 (5) 639-647.

24. Polyzois, G. L. (1990) "Improving the adaptation of denture bases by anchorage to

Marinaldo Henrique Zampieri, Rafael Leonardo Xediek Consani, Marcelo Ferraz Mesquita, Leonardo Marchini and Mateus Bertolini Fernandes dos Santos (2014), Journal of Research and Practice in Dentistry DOI: $10.5171 / 2014.948878$ 
the casts: a comparative study." Quintessence International, 21 (3) 185-190.

25. Rizzatti-Barbosa, C. M, Machado, C, Joia, F. A and Santos-Sousa, R. L. (2005) "A method to reduce tooth movement of complete dentures during microwave irradiation processing." Journal of Prosthetic Dentistry, 94 (3) 301-302.

26. Sanders, J. L, Levin, B and Reitz, P. V. (1991) "Comparison of the adaptation of acrylic resin cured by microwave energy and conventional water bath." Quintessence International, 22 (3) 181-186.

27. Santos, M. B. F, Consani, R. L. X and Mesquita, M. F. (2012) "Influence of different metal flask systems on tooth displacement in complete upper dentures." Gerodontology, 29 (1) 30-35.

28. Shukor, S. S, Juszczyk, A. S, Clark, R. K. F and Radford, D. R. (2006) "The effect of cyclic drying on dimensional changes of acrylic resin maxillary complete dentures." Journal of Oral Rehabilitation, 33 (9) 654-659.

29. Sotto-Maior, B. S, Joia, F. A, Meloto, C. B, Del Bel Cury, A. A and Rizzatti-Barbosa, C. M. (2012) "Effect of double flasking and investment methods on artificial teeth movement in complete dentures processing." Gerodontology, 29 (2) e435-439.

30. Sykora, O and Sutow, E. J. (1993) "Posterior palatal seal adaptation: influence of processing technique, palate shape and immersion." Journal of Oral Rehabilitation, 20 (1) 19-31.

31. Takamata, T and Setcos, J. C. (1989) "Resin denture bases: review of accuracy and methods of polymerization." International Journal of Prosthodontics, 2 (6) 555-562.

32. Wallace, P. W, Graser, G. N, Myers, M. L and Proskin, H. M. (1991) "Dimensional accuracy of denture resin cured by microwave energy." Journal of Prosthetic Dentistry, 66 (3) 403-408.

33. Woelfel, J. B, Paffenbarger, G. C and Sweeney, W. T. (1960) "Dimensional changes occurring in dentures during processing." Journal of American Dental Association, 61 413-430.

34. Woelfel, J. B and Paffenbarger, G. C. (1965) "Pressure-indicator-paste patterns in duplicate dentures made by different processing technics for the same patients." Journal of American Dental Association, 70 339-343.

Marinaldo Henrique Zampieri, Rafael Leonardo Xediek Consani, Marcelo Ferraz Mesquita, Leonardo Marchini and Mateus Bertolini Fernandes dos Santos (2014), Journal of Research and Practice in Dentistry, DOI: 10.5171/2014. 948878 